\title{
Caracterização fisiográfica da bacia hidrográfica do Alto Rio Jamanxim, Pará, Brasil \\ (doi:10.4136/ambi-agua.27)
}

\author{
Ana Katiuscia Pastana de Souza ${ }^{1}$; Getulio Teixeira Batista ${ }^{2}$ \\ ${ }^{1}$ Geóloga, M.Sc. em Hidrogeologia e Esp. em Gestão de Recursos Hídricos Aplicada a Bacias \\ Hidrográficas - Conj. Maguari Al. 02, nº 08 - CEP: 66823061 - Belém, PA \\ Email: anakatiuscia@gmail.com \\ ${ }^{2}$ Professor do Departamento de Ciências Agrárias e do Programa de Pós-Graduação em Ciências \\ Ambientais da Universidade de Taubaté \\ Email: getulio@agro.unitau.br.
}

\section{RESUMO}

O presente trabalho objetivou delimitar, codificar e caracterizar as sub-bacias formadoras da bacia hidrográfica do Alto Rio Jamanxim, assim como, quantificar as áreas desflorestadas e a extensão da malha viária em sua área de drenagem, para os anos de 1999 e 2005. Para o desenvolvimento do trabalho foram utilizados dados referentes às "ottobacias”, hidrografia, rodovias, modelo digital de elevação (MDE) e quatro imagens do sensor Tematic Mapper do satélite Landsat-5 (TM/Landsat-5) dos anos de 1999 e 2005. Com base em um modelo hidrológico gerado a partir do Modelo Digital de Elevação (MDE) da bacia, na escala de 1:250.000, foi delimitada sua área de drenagem, bem como calculados seus parâmetros hidrológicos. Como resultado foram delimitadas e caracterizadas nove ottobacias na área de estudo, codificadas até o nível 5 (44291 a 44299). Em relação às atividades antrópicas na área da bacia foram identificadas as áreas desflorestadas até os anos de $1999\left(635 \mathrm{~km}^{2}\right.$, correspondentes a 11\% da área da bacia) e de 2005 (1.257 $\mathrm{km}^{2}$ representando cerca de $21 \%$ da área total da bacia). Houve um incremento de desflorestamentos, entre as duas datas investigadas, de $622 \mathrm{~km}^{2}$, ou seja, $98 \%$ de aumento. Quanto à malha viária, foi mapeada uma extensão total de $1.685 \mathrm{~km}$ até 1999 e de $3.638 \mathrm{~km}$ até julho de 2005, o que representou um incremento de $116 \%$ na extensão das estradas abertas no período de 6 anos.

Palavras-chave: Desflorestamento; Geoprocessamento; Degradação; BR-163; Bacia hidrográfica; Modelo Digital de Elevação.

\section{Physiographic characterization of the Alto Rio Jamanxim Hydrographic Basin, Pará, Brazil}

\begin{abstract}
The objective of this work was to outline and to characterize the sub-basins of the Alto Rio Jamanxim hydrographic basin and to code them using the concept of "otto-basins", as well as to quantify the deforestation area and the increase in roads extension in its drainage area from 1999 to 2005. The work was based on data of river's and road's network, digital elevation model (DEM), and four TM/Landsat-5 images from 1999 and 2005. The outline of the boundaries and the hydrologic parameters of the Basin were based on a 1:250,000 DEM. Results have shown that nine sub-basins have been outlined in the study area, coded up to level 5 (otto-basin code system) and identifiers varied from 44291 to 44299 . Deforestation by human activities totaled $635 \mathrm{~km}^{2}$ (11\% of the Basin) up to 1999 and to $1,257 \mathrm{~km}^{2}$ up to 2005, therefore, an increase of $622 \mathrm{~km}^{2}$ or $98 \%$ between these two dates. Regarding the road network, a total extension of 1,685 km was mapped up to 1999 and 3,638 km up to July 2005
\end{abstract}


what corresponds to an increase of $116 \%$ in road construction inside the basin boundaries in six years.

Keywords: Deforestation; Geoprocessing; Degradation; BR-163 road; Watershed; Digital Elevation Model.

\section{INTRODUÇÃO}

Para o gerenciamento de bacias hidrográficas é condição básica conhecer suas características físicas, como área de drenagem, forma da bacia, sistema de drenagem e características do relevo. O conhecimento desses elementos é de grande utilidade prática, pois, segundo Villela e Matos (1975), eles permitem conhecer a variação no espaço dos elementos do regime hidrológico.

Outra informação importante e que poderia ser extraída utilizando técnicas de geoprocessamento, seria a subdivisão de uma bacia, facilitando o referenciamento de bases de dados para a sistematização e compartilhamento de informações (Verdin e Verdin, 1999; Verdin, 1997; Tavares et al., 2003).

Considerando a bacia hidrográfica como uma unidade básica de gerenciamento de recursos hídricos, o CNRH (Conselho Nacional de Recursos Hídricos) por meio da Resolução n³0 (11/12/1983) estabeleceu que o método desenvolvido por Pfafstetter (1989) seria adotado em âmbito nacional, como uma metodologia de codificação de bacias hidrográficas em "ottobacias", e procedimentos de subdivisões em agrupamentos de bacias hidrográficas (Brasil, 2002). Esse método de subdivisão e de codificação de bacias hidrográficas, desenvolvido no Brasil utiliza os dez algarismos do sistema decimal. O processo de hierarquização está relacionado com a área da bacia hidrográfica dos cursos d’água. Trata-se de um método natural, baseado na topografia da área drenada e na topologia (conectividade e direção) da rede de drenagem. Suas características principais são: economia de dígitos, informação topológica e aplicabilidade global. Nessa codificação, cada bacia tem uma numeração que permite informar quais as bacias hidrográficas que se localizam a montante e a jusante daquela em estudo, permite ainda a identificação do seu rio principal e seu relacionamento com as demais bacias da mesma região hidrográfica (até o nível continental).

A utilidade do método foi reconhecida pelo USGS (United States Geological Survey), que está realizando uma codificação de bacias hidrográficas de todo o planeta, com apoio das Nações Unidas, via UNEP (United Nations Environment Program). Essa iniciativa conta com a participação da SRH/MMA que priorizou o trabalho para o Brasil e introduziu outros elementos para otimizar tecnicamente os resultados. (Silva, 1999).

Esse método consiste, basicamente, no processo de hierarquização relacionado com a área de drenagem dos cursos d'água e permite o hidrorreferenciamento incluindo tratamento topológico da rede hidrográfica. Na delimitação das "ottobacias”, as áreas de contribuição de cada trecho da bacia entre uma confluência e sua nascente são identificadas e a distância média entre os trechos dos cursos d’água da rede hidrográfica calculada. Com a disponibilidade atual dos MDE, essa delimitação fica bem mais precisa pelo uso dos dados altimétricos (Barbosa et al., 2007). Silva (1999) apresenta uma descrição detalhada do método Pfafstetter de codificação de bacias, tanto por meio manual quanto digital com base em MDE.

Um importante vetor do desflorestamento presente na bacia do Rio Tapajós é a rodovia federal BR-163 (Cuiabá-Santarém), que figura como um eixo de integração fundamental para a ligação entre o Centro Oeste do País à cidade de Santarém, localizada no Baixo Rio Amazonas, região Norte. Até os dias de hoje essa integração não se desenvolveu por falta de pavimentação em grande parte da rodovia e das péssimas condições de tráfego nos trechos pavimentados, limitando o setor do agronegócio e o deslocamento da população local. 
Entretanto, está previsto o asfaltamento da rodovia na porção paraense, o que deverá acelerar o desenvolvimento e a ocupação em larga escala dessa região (Alencar et al., 2005).

Uma realidade generalizada na Amazônia é que $80 \%$ do desflorestamento estão concentrados nos primeiros $50 \mathrm{~km}$ de distância das margens das principais rodovias (Alves, 2002b; Câmara et al., 2005). Partindo-se dessa premissa, os municípios da porção paraense presentes na área de influência da BR-163 (50 km das margens) são: Novo Progresso, Altamira, Trairão, Itaituba, Rurópolis, Placas, Aveiro, Santarém, Belterra, Curuá, Monte Alegre, Alenquer e Óbidos.

Vale salientar que dentre os municípios paraenses pertencentes à área de influência da BR-163, Novo Progresso apresenta uma elevada taxa de crescimento, e com a pavimentação da rodovia essa taxa aumentará ainda mais, pois o referido município encontra-se localizado à margem da rodovia e limítrofe com o Estado do Mato Grosso que é um dos pólos agrícolas mais produtivos do país (Fearnside, 2004).

Dentro desse cenário e visando à conservação dos recursos naturais, faz-se necessária a realização de estudos de caracterização ou de diagnóstico da área a ser diretamente impactada, para permitir um planejamento de gestão e se programar uma política de uso dos recursos naturais que possibilite o desenvolvimento socioeconômico sustentável (Kohlhepp, 2002).

Sabe-se que o impacto derivado do uso do solo, repercute em todos os componentes do ciclo hidrológico, como no escoamento superficial, na recarga dos aqüíferos, na qualidade da água e no transporte de sedimentos (Mendes e Cirilo, 2001; Chaves e Alipaz, 2006; Rao et al., 2003).

Inserida nesse contexto, a bacia hidrográfica Alto Rio Jamanxim, por ser uma das áreas de cabeceiras do Rio Jamanxim, tributário do rio Tapajós, além de fazer parte dos recursos hídricos do município de Novo Progresso e, ainda, apresentar 90\% de sua área de drenagem inserida na área de influência da BR-163, merece estudo destacado (Fearnside, 2004).

Dessa forma, este artigo teve por objetivos a caracterização fisiográfica da bacia Alto Rio Jamanxim, com ênfase na estimativa do desflorestamento e abertura de estradas no período de 1999 e 2005. Especificamente, o trabalho visou: delimitar e codificar a bacia em "ottobacias" pertencentes ao Alto Rio Jamanxim; caracterizar a fisiografia da bacia e gerar mapas na escala 1:250.000 que contêm a compartimentação geológica, geomorfológica, pedológica e a cobertura vegetal, a partir do Banco de Dados Cartográficos e Temáticos do SIPAM/IBGE (1998). Foi avaliada a área desflorestada na bacia até o ano de 1999 e incremento do desflorestamento até o ano de 2005. Assim como, foi mapeada e quantificada a malha viária, com base em interpretação visual das imagens Landsat TM, para os anos de 1999 e 2005.

\section{MATERIAL E MÉTODOS}

\section{1. Área de Estudo}

Para a realização deste estudo foi selecionada a bacia hidrográfica Alto Rio Jamanxim, afluente do Rio Jamanxim, contribuinte do Rio Tapajós e, este por sua vez, afluente do Rio Amazonas. Essa área é compreendida pelos paralelos 7²1’00” e 848’36” de latitude sul e os meridianos de 5552'48” e 5457'36” de longitude oeste. Cerca de $99 \%$ da bacia estudada estão inseridos no espaço territorial do município de Novo Progresso e 1\% no município de Altamira, no sudoeste do Estado do Pará. A rodovia BR-163 (Cuiabá-Santarém), principal via de acesso na região atravessa sua área de drenagem (Figura 1). 


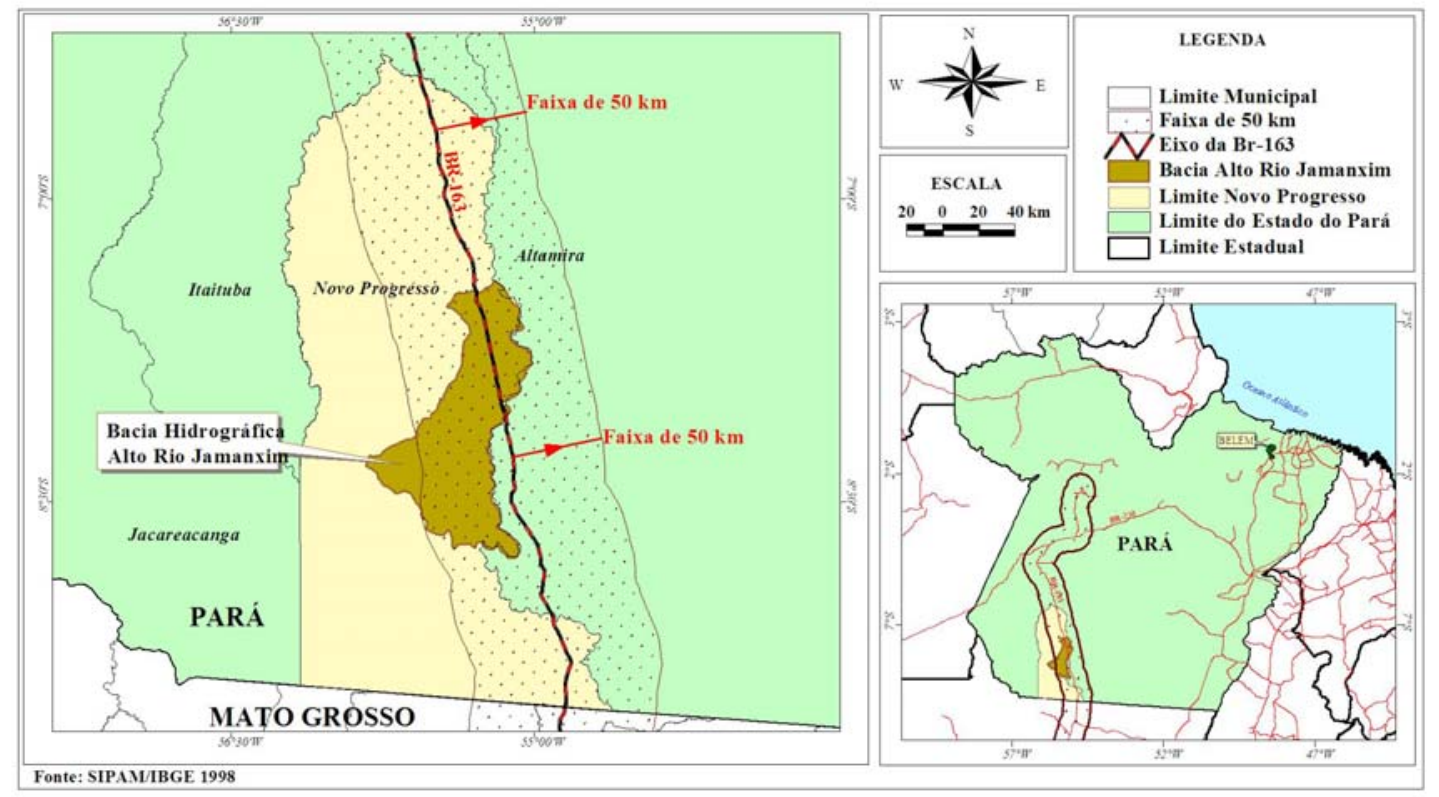

Figura 1. Localização da Bacia Hidrográfica Alto Rio Jamanxim, objeto deste estudo, do município de Novo Progresso (amarelo claro) e da área de influência da BR-163, compreendida por uma "faixa" de $50 \mathrm{~km}$ das margens da rodovia (polígono marrom define o entorno da BR-163).

\subsection{Caracterização da Bacia Alto Rio Jamanxim}

O rio principal, denominado Rio Jamanxim, é formado na Serra do Cachimbo, região centro-leste do município de Novo Progresso, e deságua no rio Tapajós, apresentando sua confluência no limite entre os municípios de Itaituba e Trairão. Os principais afluentes do Rio Jamanxim, de montante para jusante, são os rios Tocantins e Novo, localizados na margem esquerda, e rio Arari, na margem direita. Já os cursos d'água principais da bacia de estudo estão localizados na margem direita do Rio Jamanxim e são intitulados, de montante para jusante, de: Córrego Bronca, Córrego Grota Rica, Córrego Louro, Córrego Franco Freire, Córrego Luciano e Córrego Silvinho.

O clima da bacia hidrográfica do Alto Rio Jamanxim é do tipo AW, segundo a classificação de Thornwaite (Martorano e Pereira, 1993), que corresponde a um clima tropical úmido, com inverno seco e com precipitação média do mês mais seco inferior a $60 \mathrm{~mm}$. A temperatura média anual na bacia é de $25^{\circ} \mathrm{C}$, e a temperatura média mensal máxima de $32^{\circ} \mathrm{C}$ e a mínima é de $20^{\circ} \mathrm{C}$. A umidade relativa do ar média anual varia entre 80 e $85 \%$. Além de apresentar uma insolação anual de 1.800 a 2.000 horas (Brasil, 1984).

A vegetação é caracterizada pelas seguintes fitofisionomias: Floresta Estacional Decidual Submontana Dossel Emergente; Floresta Estacional Semidecidual Submontana Dossel Emergente; Floresta Ombrófila Aberta Submontana com Cipós; Floresta Ombrófila Aberta Submontana com Palmeiras; Floresta Ombrófila Densa Aluvial Dossel Uniforme; Floresta Ombrófila Densa Submontana Dossel Emergente; Refúgio Vegetacional Montano Herbácea; e Savana Florestada.

A região da bacia, objeto deste estudo, apresenta 11 unidades geológicas: Aluviões Holocênicos, Coluviões Holocênicos, Cobertura Detrito Laterítica, Suíte Intrusiva Cururu, Grupo Beneficiente, Suíte Intrusiva Creporizão, Suíte Intrusiva Parauari, Suíte Intrusiva Maloquinha, Grupo Iriri, Formação Salustiano e Formação Aruri.

As unidades geomorfológicas presentes na área são compostas por: Chapadas do Cachimbo, Planícies Amazônicas, Depressão do Rio Jamanxim-Xingu e Planaltos Residuais do Sul do Pará. 
As unidades pedológicas presentes na área da bacia Alto Rio Jamanxim são compostas por: Neossolos, Cambissolos, Gleissolos, Latossolos, Argissolos e Nitossolos.

\subsection{Material utilizado}

O material utilizado constou de um conjunto de dados temáticos e cartográficos obtidos a partir do banco de dados do SIPAM/IBGE, com os seguintes planos de informação (layers): cobertura vegetal, pedologia, geologia, geomorfologia, Modelo Digital de Elevação Hidrologicamente Consistente (MDEHC), hidrografia, estradas, “ottobacias” (nível hierárquico $=4,1: 1.000 .000$ ) e localidades, além das imagens TM/Landsat-5, órbita-ponto 227/065 e 227/066, para os anos de 1999 e 2005 e do mosaico de imagens GeoCover ortorretificado da National Aeronautics and Space Administration (NASA), usado para o georreferenciamento na escala 1:250.000.

Para a caracterização socioeconômica do município Novo Progresso, foram utilizados dados do censo do IBGE (2006). As informações sobre as estações fluviométricas e pluviométricas presentes dentro e fora da bacia do Rio Jamanxim também foram adquiridas da Agência Nacional de Águas (ANA, 2005).

Foi utilizado como interface de pré-processamento e processamento, incluindo a classificação das imagens, o aplicativo ERDAS Imagine. Para os processos de interpretação visual e geração dos mapas temáticos foi utilizado o aplicativo Arcview. Para os processos de delimitação e cálculo dos parâmetros hidrológicos foram utilizados a extensão Es_Watershed Mapping (Mapeamento de bacias hidrográficas da Vigilância Ambiental) desenvolvida para o Arcview, assim como, o aplicativo denominado WMS (Watershed Modelling System).

As principais etapas de desenvolvimento do trabalho foram executadas nos laboratórios da Divisão de Análise Ambiental do Centro Técnico e Operacional do Sistema de Proteção da Amazônia (CTO-BE / SIPAM), em Belém.

\subsection{Metodologia utilizada}

A metodologia de trabalho incluiu como componente central a caracterização fisiográfica para o diagnóstico da bacia objeto deste estudo. O fluxograma mostrado na Figura 2 caracteriza de modo sintético e hierárquico as etapas descritas na metodologia.

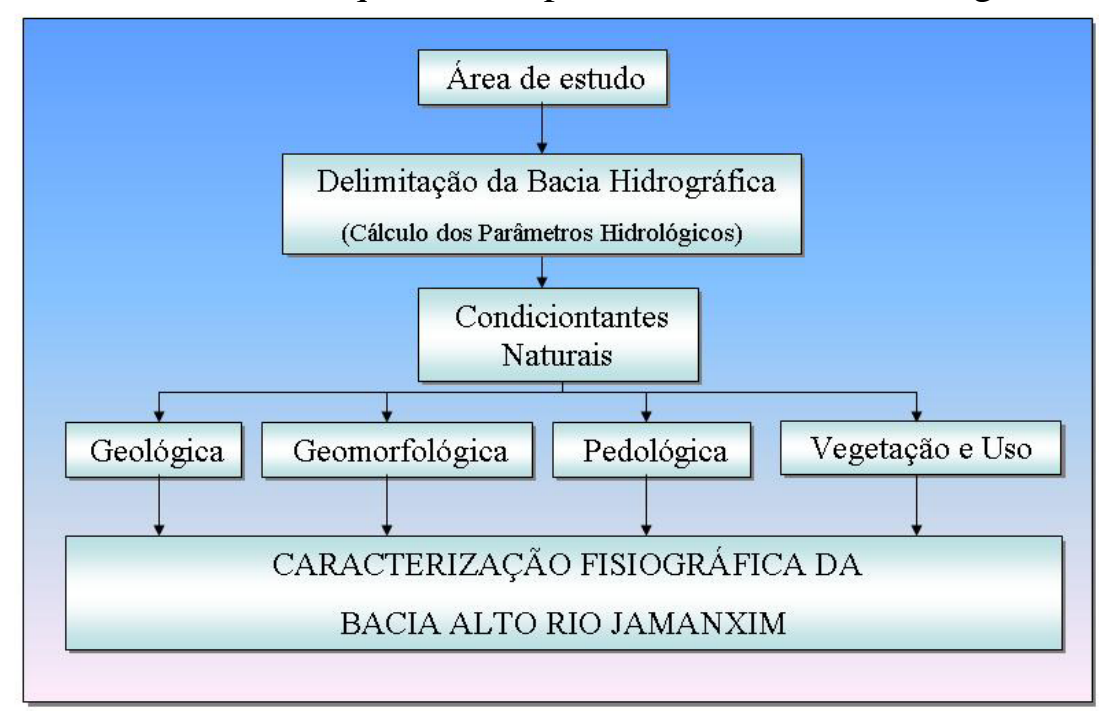

Figura 2. Fluxograma resumido da metodologia.

Para nortear os trabalhos foram utilizados técnicas e procedimentos metodológicos que foram desenvolvidos em várias fases, descritas a seguir. 


\subsection{Delimitação da Bacia Hidrográfica}

O pré-processamento e o processamento dos dados de entrada e de saída do modelo foram implementados por meio de customização do ArcView denominada Es_Watershed Mapping, a reprojeção, mosaico e recorte dos MDE's que recobrem a região de estudo, foram realizadas no ERDAS Imagine, e a geração dos limites e parâmetros das sub-bacias foi executada no ambiente do WMS. Para ilustrar a metodologia adotada foi elaborado um fluxograma geral que representa a seqüência adotada para a geração do mapa de bacias hidrográficas (Figura 3).

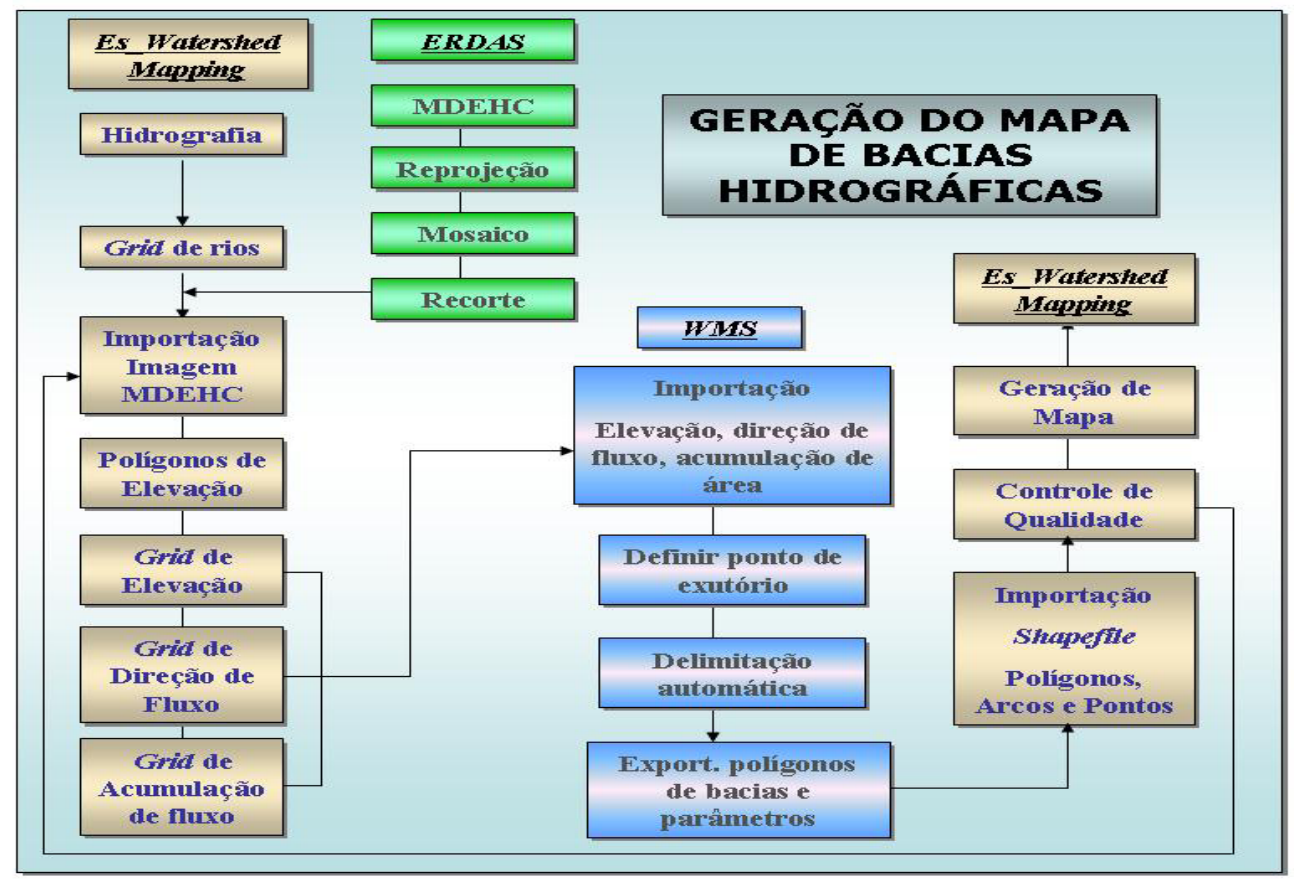

Figura 3. Fluxograma geral para a geração do mapa de bacias hidrográficas.

No ambiente do ArcView, a delimitação da bacia envolveu, inicialmente, a sobreposição dos layers de hidrografia (linha e polígono) e “ottobacias” nível 2, 3 e 4 (escala 1:1.000.000), correspondentes à área de estudo, objetivando a visualização espacial e a localização de pontos exutórios (outlets) da bacia, além dos pontos de confluência dos principais tributários. A partir disso, foi desenhado um polígono retangular e anotadas suas respectivas coordenadas do canto superior esquerdo e inferior direito, visando à identificação dos insumos necessários para a geração dos dados de entrada no software WMS.

Com as sub-bacias e os prováveis pontos de saída identificados, partiu-se para o préprocessamento desses dados, para a geração dos grids de elevação, acumulação e direção de fluxo.

No ambiente da customização Es_Watershed Mapping do ArcView, utilizou-se uma interface gráfica que permitiu o controle da seqüência de operações: (i) recuperação de dados de hidrografia; (ii) geração da grade de rio, com a determinação das células com água e sem água; (iii) importação da imagem MDE; (iv) conversão da imagem do MDE para polígonos; (v) geração da grade de elevação; (vi) geração da grade de direção de fluxo; (vii) geração da grade de acumulação de fluxo; (viii) exportação dessas três últimas grades em formato ArcInfo Grid. O MDE utilizado estava na projeção Albers Conical Equal Área/New International 1967 e foi importado como imagem no ambiente do software ERDAS Imagine.

O WMS é um aplicativo para o desenvolvimento de simulações de bacias hidrográficas, modelagem de bacias e delimitação de bacias e sub-bacias. A delimitação automática é a 
identificação do sistema de drenagem a jusante da localização dos pontos resultantes da intersecção entre a rede de drenagem e as sub-bacias (Verdin, 1997).

Com base nesse software, foram realizadas as seguintes atividades: (i) importação do grid de elevação; (ii) importação do grid de direção de fluxo; (iii) importação do grid de acumulação de fluxo; (iv) definição do ponto outlet da bacia principal; (v) conversão do MDE para arcos; (vi) delimitação automática da bacia; (vii) cálculo dos parâmetros hidrológicos; (viii) exportação de arquivos de bacias, outlets e rios (polígono, linha, ponto) (Figura 4).

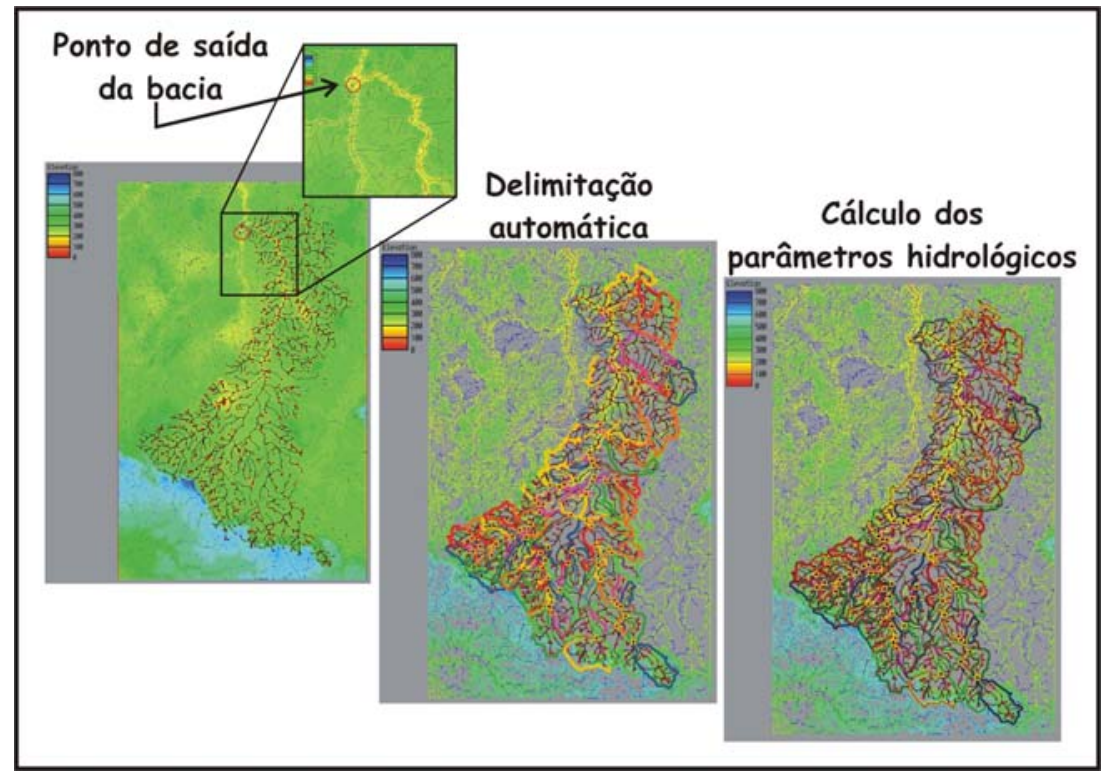

Figura 4. Ilustração dos resultados das diversas etapas na geração dos parâmetros hidrológicos com o software WMS.

\subsection{Estudos das Atividades Antrópicas com base em Sensoriamento Remoto}

Como base de referência foi utilizado o mosaico ortorretificado GeoCover da NASA, adquirido no formato compactado MrSid (.sid). Os pontos de controle foram coletados uniformemente ao longo das imagens. O Erro Médio Quadrático (RMS) e a quantidade de pontos utilizados em cada imagem são mostrados na Tabela 1.

Tabela 1. Pontos de controle obtidos nas imagens, juntamente com o RMS (m).

\begin{tabular}{ccccc}
\hline Imagem & $\begin{array}{c}\text { Órbita- } \\
\text { ponto }\end{array}$ & $\begin{array}{c}\text { Data de } \\
\text { Imageamento }\end{array}$ & $\begin{array}{c}\text { Total de } \\
\text { pontos } \\
\text { de controle }\end{array}$ & RMS \\
\hline \multirow{3}{*}{ TM/Landsat-5 } & $227 / 065$ & $10 / 08 / 1999$ & 34 & 20 \\
& $227 / 065$ & $17 / 07 / 2005$ & 29 & 18 \\
& $227 / 066$ & $10 / 08 / 1999$ & 30 & 21 \\
& $227 / 066$ & $02 / 08 / 2005$ & 25 & 18 \\
\hline
\end{tabular}

A etapa de processamento envolveu a classificação das áreas desflorestadas e a edição matricial do resultado da classificação. O método supervisionado (Maxver) foi utilizado na classificação, uma vez que havia conhecimento prévio dos padrões espectrais/espaciais das classes na imagem e no terreno, o que permitiu a seleção de amostras de treinamento representativas, seguindo metodologia descrita por Venturieri e Santos (1998). Foram classificadas as duas cenas TM/Landsat-5 referentes ao ano de 1999 (Tabela 1). Foram coletadas amostras representativas das classes de floresta, não-floresta (afloramento de rocha) e desflorestamento identificadas nas imagens de satélite. Os corpos d`água foram previamente 
removidos das imagens a serem classificadas para diminuir o nível de confusão com áreas desflorestadas queimadas recentemente.

Após a realização da classificação, foram verificados erros de inclusão e de omissão que foram eliminados por edição manual da imagem classificada. Após a edição das imagens de 1999 classificadas, deu-se início ao processo de vetorização e conversão das informações para o formato vetorial, a fim de permitir a integração (cruzamento) entre dados no aplicativo Arcview.

Na fase de interpretação visual, foram utilizados os arquivos vetoriais gerados a partir da vetorização dos dados raster provenientes da classificação supervisionada sobre as cenas TM/Landsat-5 do ano de 1999 que foram sobrepostos à imagem de 2005 para permitir a delimitação dos incrementos de áreas desflorestadas entre os anos de 1999 e 2005. Dessa forma, os incrementos identificados nas imagens do ano de 2005 foram delimitados a partir de 1999, com a digitalização na tela do computador utilizando o aplicativo Arcview.

A informação referente à malha viária para os anos de 1999 e 2005 foi extraída diretamente das imagens TM/Landsat-5, por meio da interpretação visual e da digitalização diretamente no monitor. Foi gerada inicialmente a malha viária na área da bacia até o ano de 1999. Em seguida, com base na sobreposição do mapa vetorial de 1999 sobre as imagens de 2005, foram geradas as novas vias de acesso para o ano de 2005.

Com o auxílio de um Sistema de Informação Geográfica (SIG) no ambiente do aplicativo ArcView foram sobrepostos os layers e gerados os layouts dos mapas temáticos de delimitação das bacias hidrográficas e parâmetros hidrológicos, declividade, pedologia, geomorfologia, cobertura vegetal, geologia, desflorestamento, e uso e cobertura do solo. Essa integração resultou na caracterização fisiográfica da bacia hidrográfica do Alto Rio Jamanxim objeto deste estudo.

\section{RESULTADOS E DISCUSSÃO}

A bacia hidrográfica Alto Rio Jamanxim apresentou uma área de drenagem equivalente a $5.867,5 \mathrm{~km}^{2}$, sendo que $99 \%$ de sua área correspondem ao espaço territorial do município de Novo Progresso e 1\% de Altamira, além de apresentar 90\% de sua área de drenagem inseridos na área de influência da rodovia BR-163, arbitrariamente assumida como $50 \mathrm{~km}$ de cada lado da rodovia, com base em Alves (2002a).

Dentro desse cenário, a área objeto deste estudo foi delimitada, codificada, segundo o método de Pfafstetter (1989) e caracterizada quanto ao seu meio físico, onde foram quantificadas as unidades fisiográficas.

\subsection{Características da Bacia}

A bacia em estudo foi delimitada e os seus parâmetros hidrológicos foram calculados, passando de 5888,8 $\mathrm{km}^{2}$, segundo ANA (2005), para uma área de 5867,5 km², estimada no presente trabalho, sendo dividida em 9 sub-bacias, que incluem "bacias" e "interbacias" codificadas, da foz para montante, em 44291 a 44299. Essa codificação indica que a bacia do Rio Jamanxin pertence à bacia do Rio Amazonas (nível 1, codificada com o primeiro algarismo 4), à bacia do Rio Tapajós (nível 2, codificada com o segundo algarismo, 44) e que é uma das quatro maiores e a primeira de jusante para montante (nível 3, codificada com o terceiro algarismo 442). A bacia do Alto Jamanxim é de fato uma interbacia de cabeceira do Rio Jamanxim (dígito 9 depois de 442, considerada como nível de codificação 4) e que neste trabalho foi codificada até o nível 5 e subdividida em 4 sub-bacias (dígitos 2, 4, 6 e 8 depois de 4429) e cinco interbacias (dígitos 1, 3, 5, 7 e 9 depois de 4429). A área de drenagem mínima encontrada foi de $216 \mathrm{~km}^{2}$ (ottobacia 44295) e máxima de $1.445 \mathrm{~km}^{2}$ (ottobacia 
44299). Os resultados para a bacia principal, Alto Rio Jamanxim estão na Tabela 2. Ressaltase que os cálculos foram realizados para uma escala 1:250.000.

A subdivisão realizada, mostrando a sobreposição dos layers de hidrografia e a ordem dos cursos d'água é apresentada na Figura 5. Visualiza-se a extensão da ramificação dessa bacia que foi classificada, a partir do método de Strahler (ESRI, 1997), como sendo de sexta ordem.

A densidade de drenagem da bacia, objeto deste estudo, foi estimada em $0,5 \mathrm{~km} . \mathrm{km}^{-2}$, indicando uma bacia com drenagem pobre, com densidades nas sub-bacias variando de 0,36 a $0,74 \mathrm{~km} \cdot \mathrm{km}^{-2}$. Observou-se que as ottobacias 44291 e 44293 apresentaram praticamente os mesmos valores para os parâmetros calculados.

As vertentes da bacia principal e das sub-bacias estão orientadas no sentido norte. $\mathrm{O}$ comprimento da bacia encontrado foi de 142,4 km, e o das sub-bacias entre 22,8 a 75,8 km.

Tabela 2. Características físicas da Bacia Alto Rio Jamanxim.

\begin{tabular}{l|r}
\hline \multicolumn{1}{c|}{ PARÂMETROS } & VALORES \\
\hline Área de drenagem (km²) & 5867,5 \\
Declividade média da bacia (\%) & 3,3 \\
Trajeto máximo do escoamento (km) & 214,2 \\
Declividade do trajeto máximo do escoamento (\%) & 0,2 \\
\% Sul & 43,4 \\
\% Norte & 56,6 \\
Comprimento máximo do rio (km) & 211,1 \\
Declividade média do rio mais longo & 0,1 \\
Comprimento da bacia (km) & 142,4 \\
Fator de Forma & 3,5 \\
Sinuosidade do rio principal & 1,5 \\
Perímetro (km) & 747,1 \\
Elevação média (m) & 307,9 \\
Comprimento total dos cursos d'água (km) & 2973,7 \\
Densidade de drenagem (km/km²) & 0,5 \\
Coeficiente de compacidade & 2,7 \\
Ordem da Bacia & $6^{\text {a }}$ Ordem \\
\hline
\end{tabular}

Das sub-bacias delimitadas, a "ottobacia” 44299 apresentou a maior área de drenagem $\left(1.445,1 \mathrm{~km}^{2}\right)$ e menor densidade de drenagem $\left(0,27 \mathrm{~km} \cdot \mathrm{km}^{-2}\right)$. Secundariamente, a sub-bacia 44296 apresentou maior índice de densidade de drenagem, em torno de 0,74 km. $\mathrm{km}^{-2}$ (Figura $5)$.

\subsection{Quantificação das Unidades Fisiográficas}

As unidades fisiográficas foram quantificadas em relação à cobertura vegetal, geologia, geomorfologia, pedologia e uso e ocupação do solo.

\subsubsection{Cobertura Vegetal}

A principal fitofisionomia existente na bacia, caracterizada pelo SIPAM/IBGE (1998), em 1998, era representada pela Floresta Ombrófila Aberta Submontana com Cipó, abrangendo 66,7\% da área, e, secundariamente, a Floresta Ombrófila Densa Submontana Dossel Emergente, com 13,1\%. A principal atividade antrópica era caracterizada pela pecuária que abrangia 9,2\% e, em menor proporção, pelas culturas anuais com menos de $1 \%$. As áreas de cobertura vegetal da Bacia Alto Rio Jamanxim, ano base de 1998, estão indicadas na Tabela 3. 


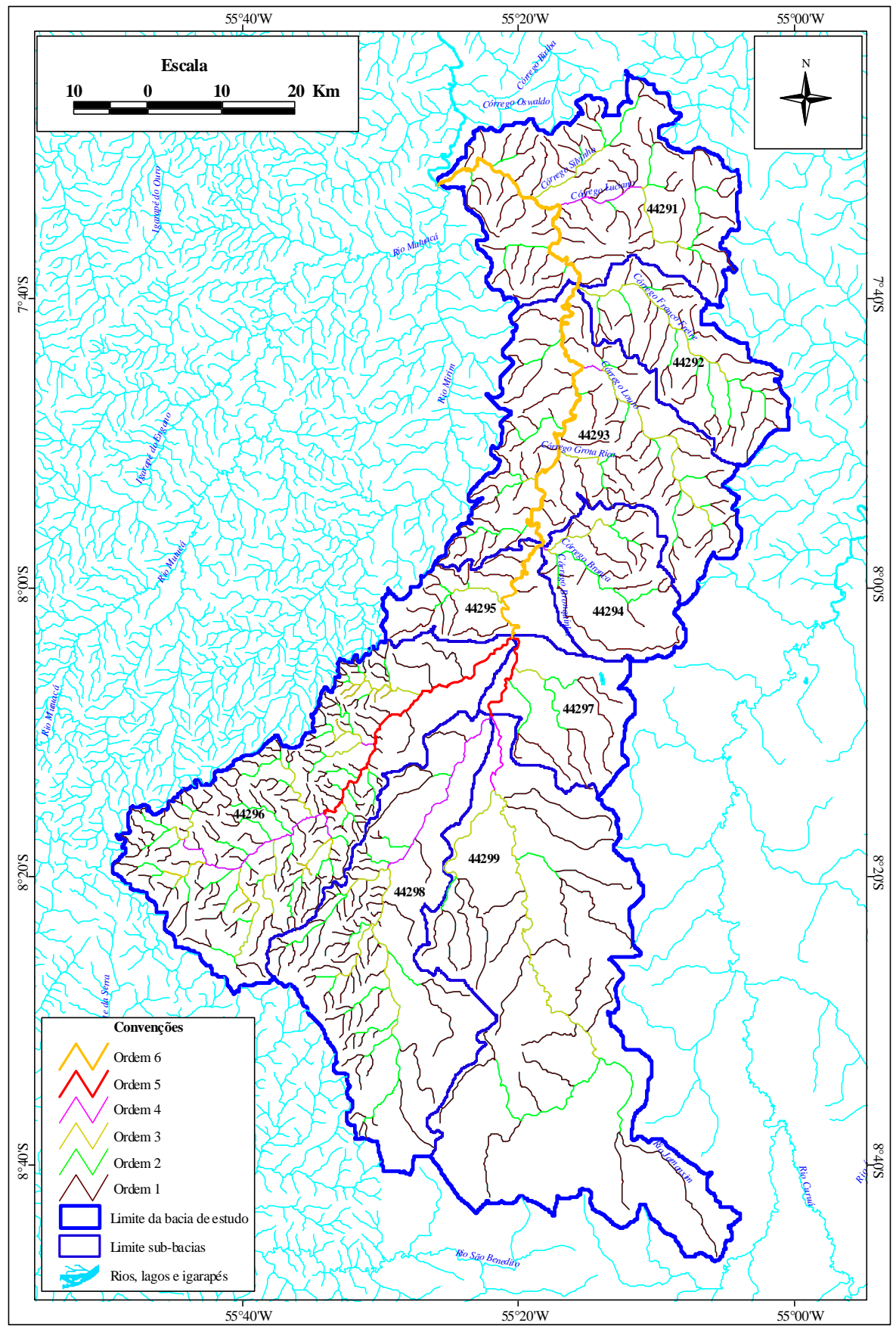

Figura 5. Subdivisão e codificação da Bacia Alto Rio Jamanxim em ottobacias (Pfafstetter, 1989) e classificação da ordem dos cursos de água dos rios segundo Strahler (1956).

\subsubsection{Contexto Geológico}

Geologicamente, a unidade dominante na área da bacia é representada pela Suíte Intrusiva Creporizão, abrangendo 46,3\%, que é composta basicamente por granitóides. Secundariamente, a Formação Salustiano, com 12,9\%, onde predominam riolitos, dacitos e andesitos associados. A quantificação das áreas, relativa às unidades geológicas, caracterizadas na Bacia Alto Rio Jamanxim, estão indicadas na Tabela 4. 
Tabela 3. Quantificação da cobertura vegetal e uso do solo.

\begin{tabular}{l|r|r}
\hline \multicolumn{1}{c|}{ Fitofisionomia } & Área $\mathbf{( k m}^{\mathbf{2}}$ & $\mathbf{( \% )}$ \\
\hline Culturas Anuais & 6,6 & 0,1 \\
Floresta Estacional Decidual Submontana Dossel Emergente & 264,0 & 4,5 \\
Floresta Estacional Semidecidual Submontana Dossel Emergente & 79,1 & 1,4 \\
Floresta Ombrófila Aberta Submontana com Cipós & $\mathbf{3 9 1 4 , 8}$ & $\mathbf{6 6 , 7}$ \\
Floresta Ombrófila Aberta Submontana com Palmeiras & 26,9 & 0,5 \\
Floresta Ombrófila Densa Aluvial Dossel Uniforme & 64,6 & 1,1 \\
Floresta Ombrófila Densa Submontana Dossel Emergente & 765,8 & 13,1 \\
Pecuária & 544,4 & 9,2 \\
Refúgio Vegetacional Montano Herbácea & 141,4 & 2,4 \\
Savana Florestada & 44,9 & 0,8 \\
\hline
\end{tabular}

Fonte: Extraído de SIPAM/IBGE (1998).

Tabela 4. Quantificação das unidades geológicas.

\begin{tabular}{l|c|c}
\hline \multicolumn{1}{c|}{ Unidade Geológica } & Área (km $\mathbf{~}^{\mathbf{2}}$ & $\mathbf{( \% )}$ \\
\hline Aluviões Holocênicos & 97,2 & 1,7 \\
Cobertura Detrito-Laterítica & 111,2 & 1,9 \\
Pleistocênica & 12,3 & 0,2 \\
Coluviões Holocênicos & 705,3 & 12,0 \\
Formação Aruri & 757,5 & 12,9 \\
Formação Salustiano & 475,4 & 8,1 \\
Grupo Beneficente & 113,4 & 1,9 \\
Grupo Iriri & 15,3 & 0,3 \\
sem informação & $\mathbf{2 7 1 3 , 6}$ & $\mathbf{4 6 , 3}$ \\
Suíte Intrusiva Creporizão & 0,2 & Sem representatividade \\
Suíte Intrusiva Cururu & 458,3 & 7,8 \\
Suíte Intrusiva Maloquinha &
\end{tabular}

Fonte: Extraído de SIPAM/IBGE (1998).

\subsubsection{Unidades Geomorfológicas}

As unidades geomorfológicas encontradas na área da bacia estão representadas pelas Chapadas do Cachimbo, Planícies Amazônicas, Depressão do Rio Jamanxim-Xingu e Planaltos Residuais do Sul do Pará, tendo sido quantificadas e apresentadas na Tabela 5.

Tabela 5. Quantificação das unidades geomorfológicas.

\begin{tabular}{l|c|c|}
\hline \multicolumn{1}{|c|}{ Unidade Geomorfológica } & $\begin{array}{c}\text { Área } \\
\left.\mathbf{( k m}^{2}\right)\end{array}$ & $\mathbf{( \% )}$ \\
\hline Chapadas do Cachimbo & 330,0 & 5,6 \\
Planícies Amazônicas & 109,2 & 1,9 \\
Depressão do Rio Jamanxim-Xingu & $\mathbf{5 1 4 9 , 0}$ & $\mathbf{8 7 , 8}$ \\
Planaltos Residuais do Sul do Pará & 264,0 & 4,5 \\
\hline
\end{tabular}

Fonte: Extraído de SIPAM/IBGE (1998).

Na bacia ocorre predominância da unidade denominada Depressão do rio JamanximXingu, em 87,8\% da área. Principalmente, ocorrendo formas de dissecação caracterizadas por um conjunto de formas de relevo de topos convexos, em geral esculpidas em rochas cristalinas e, eventualmente, também em sedimentos, às vezes, denotando controle estrutural, definidas por vales pouco profundos, apresentando vertentes de declividade suave.

\subsubsection{Classes de Solos}

As quantificações de todas as unidades pedológicas, caracterizadas na bacia, estão indicadas na Tabela 6. Observou-se que os solos predominantes foram os Argissolos (Podzólico Vermelho-Amarelo), que ocorrem em 73,7\% da área. 
Tabela 6. Quantificação das unidades pedológicas.

\begin{tabular}{|c|c|c|c|}
\hline \multicolumn{2}{|c|}{ Unidade de Solo } & \multirow{2}{*}{ Área $\left(\mathbf{k m}^{2}\right)$} & \multirow{2}{*}{$(\%)$} \\
\hline Sipam/IBGE (1998) & EMBRAPA (1999) & & \\
\hline Afloramento de Rochas & Afloramento de Rochas & 317,4 & 5,4 \\
\hline Areia Quartzosa & Neossolos & 134,6 & 2,3 \\
\hline Cambissolo & Cambissolos & 15,3 & 0,3 \\
\hline Gleissolo & Gleissolos & 194,8 & 3,3 \\
\hline Latossolo Vermelho-Amarelo & Latossolos & 131,2 & 2,2 \\
\hline Podzólico Vermelho-Amarelo & Argissolos & 4327,0 & 73,7 \\
\hline Podzólico Vermelho-Escuro” & Nitossolos & 479,9 & 8,2 \\
\hline Solo Litólico & Neossolos & 252,2 & 4,3 \\
\hline
\end{tabular}

Fonte: Adaptado de SIPAM/IBGE (1998) ao Sistema Brasileiro de Classificação de Solos (EMBRAPA, 1999).

\subsubsection{Atividades Antrópicas}

A classificação digital com o objetivo de mapear as áreas de desflorestamento resultou em erros de omissão e inclusão em algumas porções da imagem. Assim, foi necessária uma edição pelo analista das imagens classificadas a fim de corrigir confusões ou erros inerentes ao processo. As principais confusões encontradas foram descontinuidades em classes que na realidade não poderiam ser descontínuas (estradas, desflorestamentos) e classificação de áreas de solo exposto natural como se fossem áreas desmatadas (e.g. banco de areia).

No ano de 1999, foi constatada a existência de um padrão de desflorestamento mais concentrado na porção norte da bacia do Alto Jamanxim em áreas adjacentes ao eixo da rodovia. Na porção sul, que não é seccionada pela rodovia, observou-se um padrão de menor freqüência marcado por desflorestamentos médios e grandes. O mapa de desflorestamento é composto por três classes representativas (floresta, não-floresta e desflorestamento). Foram gerados os seguintes mapas: i) mapa do desflorestamento acumulado até 1999 (Figura 6a) e do desflorestamento acumulado até 2005 (Figura 6b).

O mapa temático apresentado na Figura 6c mostra a distribuição espacial do incremento do desflorestamento entre os anos de 1999 e 2005 na área da bacia hidrográfica. Observa-se o aparecimento de novos desflorestamentos em áreas de floresta. A porção oeste passou a ser bastante desflorestada nesse período.

$\mathrm{Na}$ área total da bacia hidrográfica do Alto Jamanxim $\left(5.867,5 \mathrm{~km}^{2}\right)$ foram quantificados 172 polígonos de área sem a cobertura original até o ano de 1999, o que representava uma área já convertida em classes de uso da terra (principalmente uso agropecuário) de $635 \mathrm{~km}^{2}$ (11\% da área da bacia). Já no ano de 2005, foram mapeados 419 polígonos de incremento da remoção da cobertura vegetal ocorrida entre os anos de 1999 e 2005. Foram quantificados, em 2005, um desflorestamento acumulado de $1.257 \mathrm{~km}^{2}$ representando cerca de $21 \%$ da área total da bacia do Alto Jamanxim associado a um incremento, entre as duas datas investigadas, de $622 \mathrm{~km}^{2}$, ou seja, $98 \%$ de aumento. Observações de campo revelaram que o desflorestamento ocorrido entre 1999 e 2005 foi convertido para exploração agropecuária e crescimento urbano, entre outras. Parte da área desflorestada foi abandonada e encontrava-se em regeneração. A Tabela 7 mostra os valores calculados do desflorestamento nos anos de 1999 e 2005 para a área da bacia do Alto Jamanxim e para as nove sub-bacias delimitadas. 
SOUZA, A. K. P.; BATISTA, G. T. Caracterização fisiográfica da bacia hidrográfica do Alto Rio Jamanxim, Pará, Brasil. Ambi-Agua, Taubaté, v. 2, n. 2, p. 69-87, 2007. (doi:10.4136/ambi-agua.27)

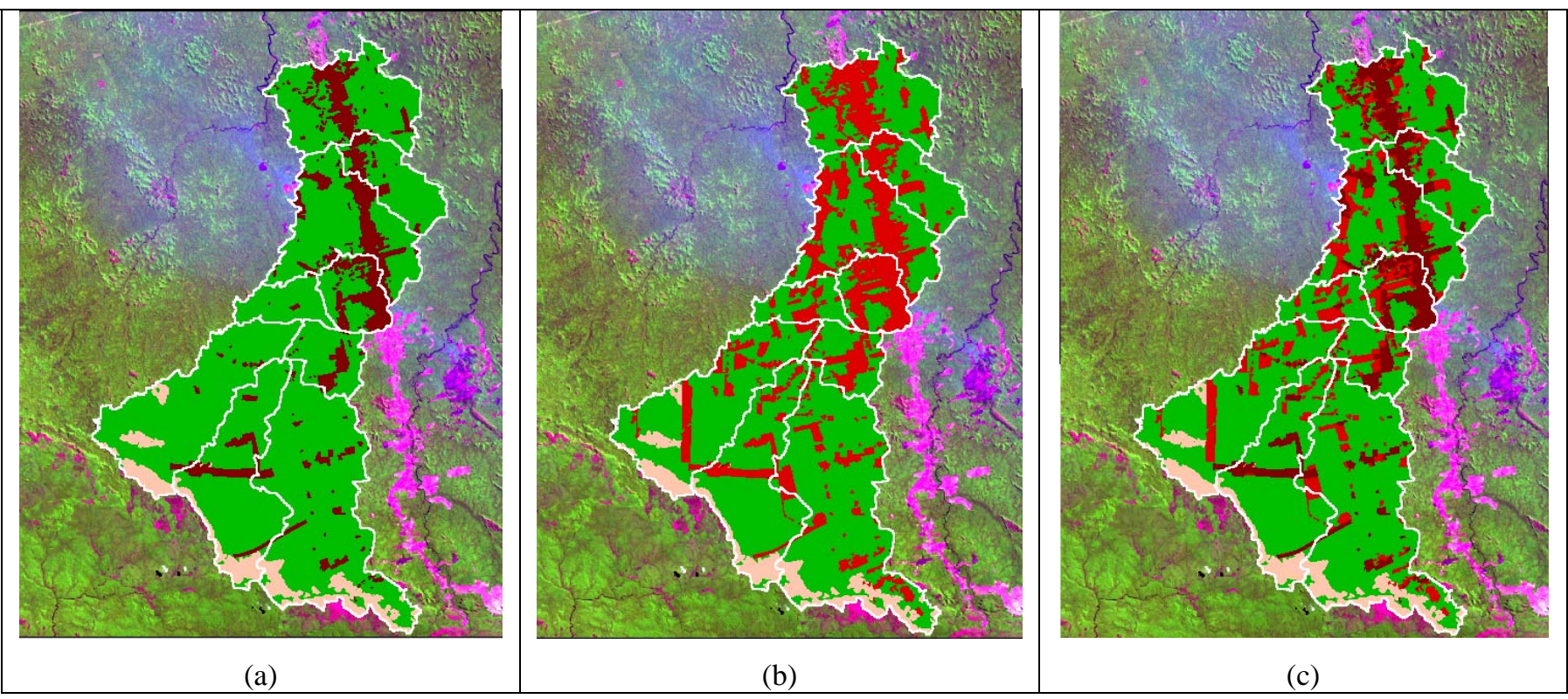

Figura 6. Mapa do desflorestamento acumulado: (a) até 1999; (b) até 2005: (c) incremento do desflorestamento entre 1999 e 2005 na bacia hidrográfica do Alto Jamanxim; (marrom=desflorestamento até 1999, vermelho=desflorestamento até 2005 , verde=floresta e bege=não-floresta).

Dentre as sub-bacias mais afetadas pelo desflorestamento ao longo do período de estudo, destacam-se negativamente as “ottobacias” 44295 e 44296 que tiveram um incremento do desflorestamento, entre 1999 e 2005, em torno de 1246\% e 860\%, respectivamente. As subbacias mais preservadas nos últimos anos foram 44298 e 44294 . Mesmo assim, tiveram incrementos de $45 \%$ e de $47 \%$, respectivamente. Os mapas temáticos: desflorestamento detectados no ano de 1999 (Figura 6a), desflorestamento detectado no ano de 2005 (Figura 6b) e incremento do desflorestamento (Figura 6c) nas nove sub-bacias do Alto Jamanxim, demonstram o panorama crescente atual da remoção da cobertura vegetal no período avaliado neste trabalho.

Os desflorestamentos ocorridos na área da bacia estão geralmente associados à abertura de estradas para acesso às áreas de interesse econômico para extração de madeira. Outro vetor de expansão do desflorestamento na área da bacia do Alto Jamanxim são os rios, nos quais desflorestamentos pequenos e médios têm se intensificado desde 1999. Nas porções norte e central da bacia ocorre uma maior densidade de desflorestamentos, principalmente na margem esquerda do rio Jamanxim.

Igualmente, foram analisadas as estradas vicinais dentro da bacia que somaram uma extensão total estimada de $3637,5 \mathrm{~km}$, até julho de 2005. Isso representa um aumento de estradas abertas em torno de 54\%, em um período de 6 anos (Tabela 8). O mapa contendo o resultado desta variação é apresentado na Figura 7 (a) para o ano de 1999 e 7 (b) para o ano de 2005. 
SOUZA, A. K. P.; BATISTA, G. T. Caracterização fisiográfica da bacia hidrográfica do Alto Rio Jamanxim, Pará, Brasil. Ambi-Agua, Taubaté, v. 2, n. 2, p. 69-87, 2007. (doi:10.4136/ambi-agua.27)

Tabela 7. Áreas das sub-bacias, dos desflorestamentos (até 1999 e até 2005) e incrementos de desflorestamento nesse período para as sub-bacias codificadas.

\begin{tabular}{|c|c|c|c|c|}
\hline Sub-Bacias & $\begin{array}{c}\text { Área das Sub-bacias } \\
\left(\mathrm{km}^{2}\right)\end{array}$ & $\begin{array}{c}\text { Desflorestamento em } \\
1999 \\
N^{\circ} \text { de Polígonos } \\
\text { (ha) } \\
\end{array}$ & $\begin{array}{c}\text { Desflorestamento em } \\
2005 \\
N^{\circ} \text { de Polígonos } \\
\text { (ha) }\end{array}$ & $\begin{array}{c}\text { Incremento } \\
\text { (ha) } \\
\text { (\%) }\end{array}$ \\
\hline 44291 & 723,5 & $\begin{array}{c}53 \text { polígonos } \\
121,4\end{array}$ & $\begin{array}{c}79 \text { polígonos } \\
201,3\end{array}$ & $\begin{array}{c}80,0 \\
65,9 \% \\
\end{array}$ \\
\hline 44292 & 346,8 & $\begin{array}{c}18 \text { polígonos } \\
52,2\end{array}$ & $\begin{array}{c}27 \text { polígonos } \\
83,6\end{array}$ & $\begin{array}{r}31,4 \\
60,2 \% \\
\end{array}$ \\
\hline 44293 & 770,5 & $\begin{array}{c}53 \text { polígonos } \\
159,0\end{array}$ & $\begin{array}{l}67 \text { polígonos } \\
294,2\end{array}$ & $\begin{array}{l}135,2 \\
85,0 \% \\
\end{array}$ \\
\hline 44294 & 288,6 & $\begin{array}{l}24 \text { polígonos } \\
128,6\end{array}$ & $\begin{array}{c}27 \text { polígonos } \\
189,8\end{array}$ & $\begin{array}{c}61,2 \\
47,6 \% \\
\end{array}$ \\
\hline 44295 & 216,0 & $\begin{array}{l}4 \text { polígonos } \\
\text { 3,8 }\end{array}$ & $\begin{array}{l}19 \text { polígonos } \\
51,1\end{array}$ & $\begin{array}{c}47,3 \\
1246,4 \%\end{array}$ \\
\hline 44296 & 966,1 & $\begin{array}{c}13 \text { polígonos } \\
12,6\end{array}$ & $\begin{array}{c}44 \text { polígonos } \\
120,9\end{array}$ & $\begin{array}{c}108,3 \\
860,4 \% \\
\end{array}$ \\
\hline 44297 & 271,3 & $\begin{array}{c}15 \text { polígonos } \\
37,0\end{array}$ & $\begin{array}{l}29 \text { polígonos } \\
76,3\end{array}$ & $\begin{array}{c}39,3 \\
106,2 \% \\
\end{array}$ \\
\hline 44298 & 839,5 & $\begin{array}{l}8 \text { polígonos } \\
64,7\end{array}$ & $\begin{array}{c}52 \text { polígonos } \\
93,6\end{array}$ & $\begin{array}{c}29,0 \\
44,8 \% \\
\end{array}$ \\
\hline 44299 & $1.445,2$ & $\begin{array}{c}37 \text { polígonos } \\
56,0\end{array}$ & $\begin{array}{l}75 \text { polígono } \\
146,4\end{array}$ & $\begin{array}{c}90,4 \\
161,3 \% \\
\end{array}$ \\
\hline Bacia & Área Total & $\begin{array}{c}\text { Desflorestamento } \\
1999 \\
\end{array}$ & Desflorestamento 2005 & $\begin{array}{c}\text { Incremento } \\
2005-1999 \\
\end{array}$ \\
\hline $\begin{array}{l}\text { Alto Jamanxim } \\
\text { (4429) }\end{array}$ & $5.867,5 \mathrm{~km}^{2}$ & $\begin{array}{c}635,3 \mathrm{~km}^{2} \\
10,8 \%\end{array}$ & $\begin{array}{c}1257,3 \mathrm{~km}^{2} \\
21,4 \%\end{array}$ & $\begin{array}{c}622,0 \mathrm{~km}^{2} \\
97,9 \%\end{array}$ \\
\hline
\end{tabular}

Tabela 8. Quantificação da extensão das estradas em cada ottobacia.

\begin{tabular}{c|c|c|c}
\hline Ottobacia & $\begin{array}{c}\text { Extensão de } \\
\text { Estradas até } \\
\mathbf{1 9 9 9}(\mathbf{k m})\end{array}$ & $\begin{array}{c}\text { Extensão de estradas } \\
\text { entre 1999 e 2005 } \\
\mathbf{( k m})\end{array}$ & $\begin{array}{c}\text { Extensão total de } \\
\text { estradas } \mathbf{( k m )}\end{array}$ \\
\hline 44291 & 200,3 & 124,7 & 324,9 \\
44292 & 129,0 & 136,5 & 265,5 \\
44293 & 417,4 & 351,5 & 768,9 \\
44294 & 372,5 & 189,5 & 562,0 \\
44295 & 31,0 & 121,0 & 152,0 \\
44296 & 155,6 & 313,6 & 469,2 \\
44297 & 53,9 & 190,9 & 244,8 \\
44298 & 85,0 & 228,1 & 313,1 \\
44299 & 239,9 & 297,2 & 537,2 \\
\hline Total Alto Jamanxim & $\mathbf{1 6 8 4 , 6}$ & $\mathbf{1 9 5 2 , 9}$ & $\mathbf{3 6 3 7 , 5}$ \\
\hline
\end{tabular}


SOUZA, A. K. P.; BATISTA, G. T. Caracterização fisiográfica da bacia hidrográfica do Alto Rio Jamanxim, Pará, Brasil. Ambi-Agua, Taubaté, v. 2, n. 2, p. 69-87, 2007. (doi:10.4136/ambi-agua.27)

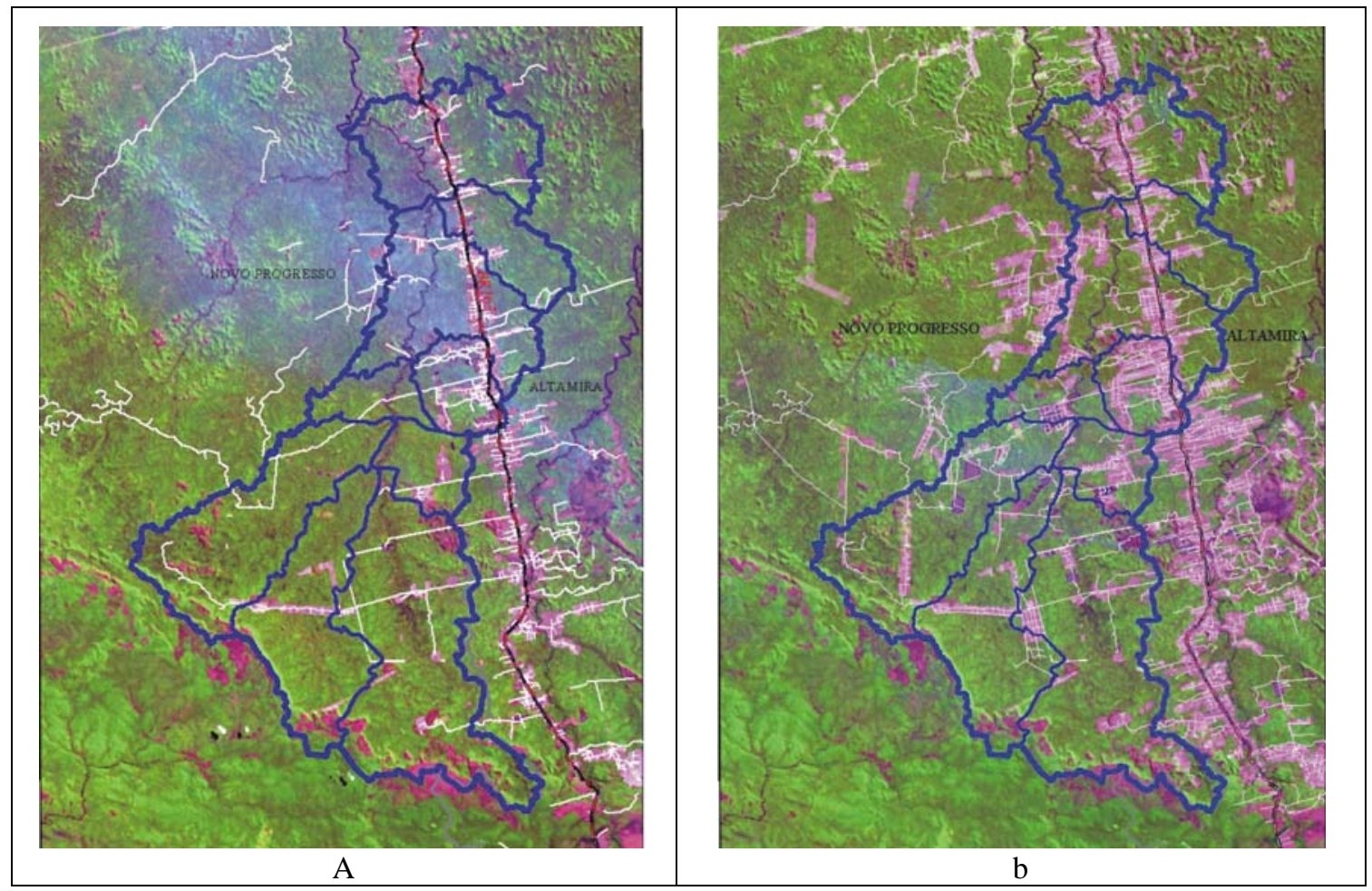

Figura 7. Mapa da malha viária entre (a) 1999 e (b) 2005 na área da bacia hidrográfica do Alto Jamanxim e ottobacias.

O maior incremento percentual na abertura de estradas foi na bacia 44295, onde houve um aumento de 79,6\% e, em segundo lugar, na bacia 44297, com 78,0\%. Porém, visualizando a Figura 8, pode ser observado que a bacia 44293 apresentou a maior extensão de estradas em sua área de drenagem.

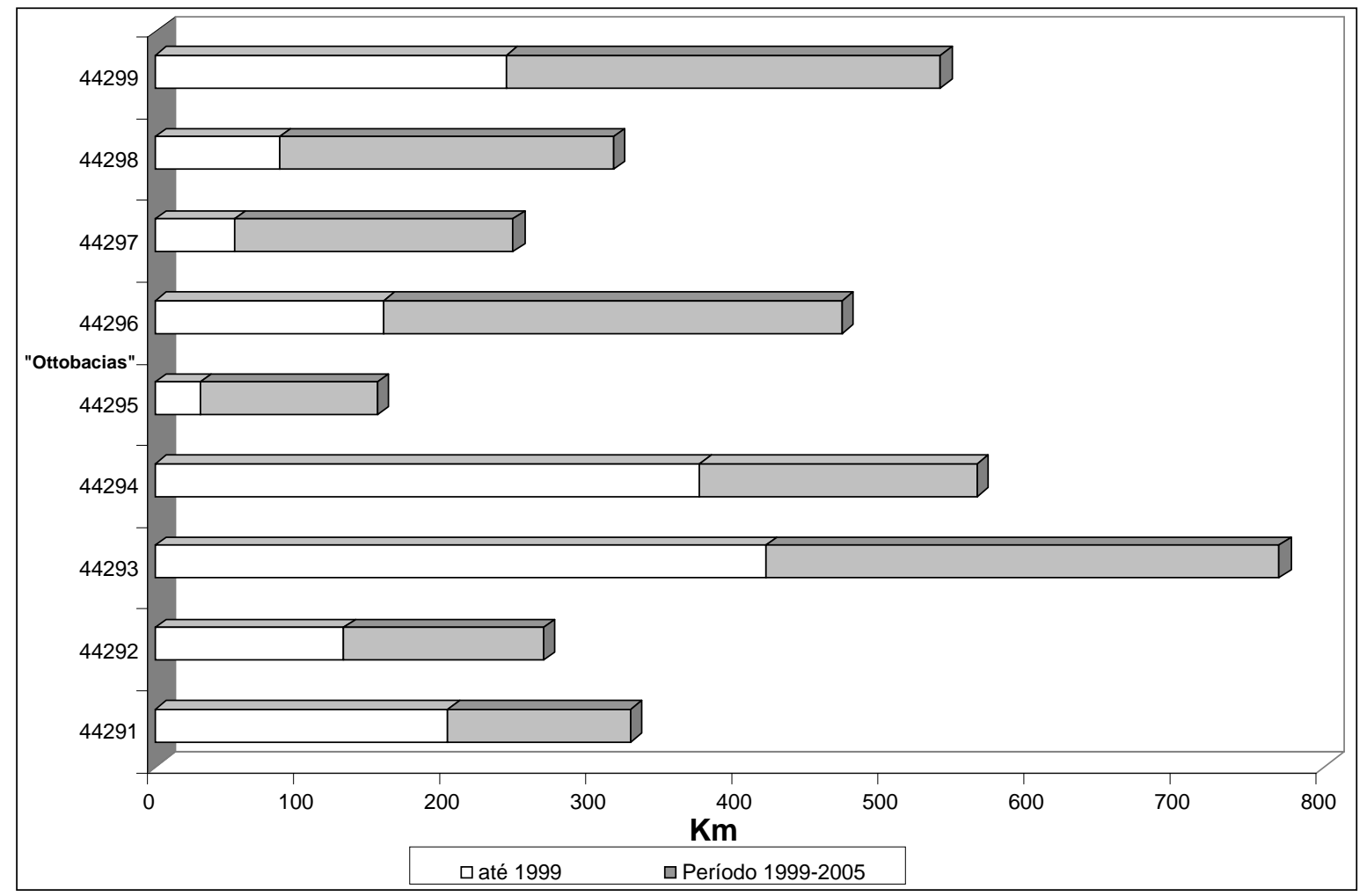

Figura 8. Extensão da malha viária até 1999 e até julho de 2005, por ottobacia. 
Observou-se ainda, que a construção de estradas ou caminhos apresentou um sentido leste oeste, em formato de "espinha de peixe" sem levar em consideração a direção da drenagem, é notório que o melhor local para a construção de estradas é no divisor hidrográfico para minimizar o impacto na drenagem (Silva Jr. e Mattos, 2003).

\section{CONCLUSÃO}

A área estimada para a bacia resultou em uma diferença de $20 \mathrm{~km}^{2}$ em relação ao limite previamente conhecido para escala 1:1.000.000, o que representa uma diferença significativa para planejamento e gestão. O método de codificação (ottobacias) permitiu a hierarquização de nove bacias as quais variaram de 44291 a 44299, e as bacias aparentemente homogêneas apresentaram valores dos parâmetros hidrológicos similares.

As unidades fisiográficas predominantes na área da bacia são: i) Vegetação: Floresta Ombrófila Aberta Submontana com cipós ocupando 66,7\%; ii) Geológica: Suíte Intrusiva Creporizão, ocorrendo em 46,3\% da área da bacia; iii) Geomorfológica: Depressão do Rio Jamanxim-Xingu; ocupando quase que totalmente $(87,8 \%)$ da bacia; iv) Solos: Argissolos (Podzólico Vermelho Amarelo), ocorrem em 73,7\% da bacia Alto Rio Jamanxim.

No ano de 1999, foi constatada a existência de um padrão de desflorestamento mais concentrado na porção norte da bacia do Alto Jamanxim em áreas adjacentes ao eixo da rodovia. Enquanto a porção sul, que não é seccionada pela rodovia, apresentava um padrão de desflorestamento menos intenso, com talhões médios e grandes.

Até o ano de 1999, foi quantificado uma área já convertida em classes de uso da terra (principalmente uso agropecuário) de aproximadamente $635 \mathrm{~km}^{2}$ (11\% da área da bacia) e em 2005 foi quantificado um desflorestamento acumulado de $1.257 \mathrm{~km}^{2}$ representando cerca de $21 \%$ da área total da bacia, associado a um incremento, entre as duas datas investigadas, de aproximadamente $622 \mathrm{~km}^{2}$, ou seja, 98\% de aumento. Entre 1999 e 2005 esse desflorestamento foi convertido principalmente para uso para agropecuária, área urbana, entre outras.

As “ottobacias" 44295 e 44296 tiveram destaque negativo por terem sofrido um incremento de áreas desflorestadas, entre 1999 e 2005, de 1246\% e 860\%, respectivamente. As sub-bacias mais preservadas nos últimos anos foram 44298 e 44294, mesmo assim, com incrementos em torno de $45 \%$ e $47 \%$, respectivamente.

Os desflorestamentos ocorridos na área da bacia estão geralmente associados à criação de estradas vicinais com a finalidade de acesso às áreas de interesse para extração de madeira. Outro vetor de expansão do desflorestamento na área da bacia do Alto Jamanxim são os rios, em que desflorestamentos pequenos e médios têm sido intensificados desde 1999. Nas porções norte e central da bacia, ocorre uma maior densidade de desflorestamentos, principalmente na margem esquerda do Rio Jamanxim.

A malha viária mapeada apresentou uma extensão total de $3638 \mathrm{~km}$, até julho de 2005. Observou-se um aumento de estradas abertas em torno de 54\%, no período de estudo (6 anos). O maior percentual na abertura de estradas foi na bacia 44295, onde um houve um aumento de 79,6\%, em segundo lugar, a bacia 44297, com 78\%. Observou-se ainda, que as estradas ou caminhos apresentaram um sentido dominante leste-oeste, em formato de "espinha de peixe" sem levar em consideração a direção dominante da drenagem, portanto, favorecendo erosão e dificultando a manutenção das estradas.

Para a elaboração do plano de gestão dessa bacia, recomenda-se que os dados sejam validados em campo, além da realização do monitoramento da vazão na confluência do rio principal, denominado Rio Jamanxim com o Rio Mutuacá, para a realização do cálculo de disponibilidade hídrica. 


\section{AGRADECIMENTOS}

Ao Conselho Nacional de Desenvolvimento Científico e Tecnológico pelo apoio que viabilizou a participação da autora principal no Curso de Especialização a Distância em Gestão de Recursos Hídricos em Bacias Hidrográficas da Pró-Reitoria de Pesquisas e PósGraduação da Universidade de Taubaté, Processo CNPq/CT-Hidro Nº504304/2003-8 (Edital MCT/CNPq/CT-Hidro No3/2003 - Capacitação de Recursos - Chamada 1).

Ao SIPAM - Sistema de Proteção da Amazônia, Centro Técnico e Operacional de Belém, por facilitar o acesso às informações e pelo apoio operacional que foi de extrema importância para a realização deste trabalho.

\section{REFERÊNCIAS}

AGÊNCIA NACIONAL DE ÁGUAS. HidroWeb: sistema de informações hidrológicas. 2005. Disponível em: <http://hidroweb.ana.gov.br>. Acesso em: 12 set. 2006.

ALENCAR, A.; MICOL, L.; REID, J; AMEND, M. O.; ZEIDEMANN, V; SOUSA JÚNIOR, W. C. A pavimentação da BR-163 e os desafios à sustentabilidade: uma análise econômica, social e ambiental. Belo Horizonte: CSF, 2005. Disponível em: $<$ http://www.estacaovida.org.br/pdf/pavimentacaobr163.pdf.>. Acesso em: 18 mar. 2007.

ALVES, D. S. An analysis of the geographical patterns of deforestation in Brazilian Amazonia in the 1991-1996 period. In: WOOD, C. H.; PORRO, R. (Org.). Land use and deforestation in the Amazon. Gainesville: University Press of Florida, 2002a. p. 95-161.

ALVES, D. S. Space-time dynamics of deforestation in Brazilian Amazônia. International Journal of Remote Sensing, London, v. 23, p. 2903-2908, 2002b.

BARBOSA, F. L. R.; SILVA, M. A.; TEIXEIRA, A. de A.; PRADO, A. do; SCHERERWARREN, M.; RIBEIRO, R. M. P. Delimitação de ottobacias a partir de modelo digital de elevação hidrologicamente consistente para a bacia do Verde Grande. In: SIMPÓSIO BRASILEIRO DE SENSORIAMENTO REMOTO, 13., 21-26 abril 2007, Florianópolis. Anais... São José dos Campos: INPE, 2007. p. 3271-3278.

BRASIL. Ministério da Integração Nacional. Secretaria de Políticas de Desenvolvimento Regional. Grupo de Trabalho Interministerial. Plano de desenvolvimento sustentável para a área de influencia da BR-163. Brasília: MIN, julho de 2004. Disponível em: $<$ http://www.integracao.gov.br>. Acesso em: 15 jul. 2006.

BRASIL. Ministério do Meio Ambiente. Secretaria de Recursos Hídricos. Recursos hídricos: conjunto de normas legais. 2. ed. Brasília: Secretaria de Recursos Hídricos, 2002. 141p.

BRASIL. Superintendência do Desenvolvimento da Amazônia. Projeto de Hidrologia e Climatologia da Amazônia. Atlas Climatológico da Amazônia Brasileira. Belém: SUDAM, 1984. (Publicação, 39).

CÂMARA, G.; AGUIAR, A. P. D.; ESCADA, M. I.; AMARAL, S.; CARNEIRO, T.; MONTEIRO, A. M. V. et al. Amazonian deforestation models. Science, v. 307, n. 5712, p. 1043-1044, 2005. 
CHAVES, H. M. L.; ALIPAZ, S. An integrated indicator based on basin hydrology, environment, life, and policy: the watershed sustainability index. Water Resource Management, Athens, v. 21, n. 5, p. 883-895, may 2007.

EMPRESA BRASILEIRA DE PESQUISA AGROPECUÁRIA. Sistema brasileiro de classificação de solos. Rio de Janeiro: EMBRAPA Solos, 1999. 412 p.

ESRI. Arc-Info version 7.3. Redlands: Esri, 1997. Software.

FERNSIDE, P. M. Desmatamento na Amazônia. In: SIMPÓSIO BRASILEIRO DE PÓSGRADUAÇÃO EM ENGENHARIA FLORESTAL, 3. / ENCONTRO AMAZÔNICO DE CIÊNCIAS FLORESTAIS, 1., 22 a 26 de junho de 2004, Manaus. Resumos... Manaus: INPA, 2004. Disponível em: <http://www.philip.inpa.gov.br/ publ_livres/Resumos\%20e\%20anais /Unpublished\% 20abstracts/Fearnside\%20resumodesmatamento.pdf $>$. Acesso em: 18 mar. 2007.

INSTITUTO BRASILEIRO DE GEOGRAFIA E ESTATÍSTICA. IBGE Cidades@. 2006. Disponível em: <http://www.ibge.gov.br/cidadesat/default.php>. Acesso em jul. 2007.

KOHLHEPP, G. Conflitos de interesse no ordenamento territorial da Amazônia brasileira. Estudos Avançados, São Paulo, v. 16, n. 45, 2002. Disponível em: <http://www.scielo. br/scielo.php?pid=S0103-40142002000200004\&script=sci_arttext $>$. Acesso em: 18 mar. 2007.

MARTORANO, L. G.; PEREIRA, L. Estudos climáticos do Estado do Pará, classificação climática (Köppen) e deficiência hídrica (Thornthwaite). Belém: SUDAM/EMBRAPA, 1993.73p.

MENDES, C. A. B.; CIRILO, J. A. Geoprocessamento em recursos hídricos: princípios, integração e aplicação. Porto alegre: ABRH, 2001.

PFAFSTETTER, O. Classificação de bacias hidrográficas: metodologia de codificação. Rio de Janeiro: Departamento Nacional de Obras de Saneamento (DNOS), 1989. p. 19. Manuscrito não publicado.

RAO, S. S.; MURTHY, Y. V. N. K.; ADIGA, S.; AMMINEEDU, E. Performance index for watershed development. The Journal of Indian Geophysical Union, Hyderabad, v. 7, n. 4, p. 239-247, 2003

SILVA JUNIOR, J. A.; MATTOS, J. T. de. Uso de técnicas de sensoriamento remoto na elaboração de projetos de traçado de rodovias. In: SIMPÓSIO BRASILEIRO DE SENSORIAMENTO REMOTO, 11., 05 a 10 de abril 2003, Belo Horizonte. Anais... São José dos Campos: INPE, 2003. p. 1943-1950.

SILVA, P. A. Classificação e codificação das bacias hidrográficas brasileiras segundo o método pfafstetter, com uso de geoprocessamento. In: ENCONTRO DAS ÁGUAS, 2., 15 a 18 de junho 1999, Montevidéu. Resúmenes y Trabahos presentados... Montevidéu: IICA, 1999. Disponível em: <http://www.iica.org.uy/16-6-pan1pon10.htm>. Acesso em: julho 2007.

SISTEMA DE PROTEÇÃO DA AMAZÔNIA. Base de dados georreferenciados do Centro Técnicos e Operacional de Belém. 1998. 1 CD-ROM.

STRAHLER, A. N. Quantitative slope analysis. Bulletin of the Geological Society of América, Rochester, v. 67, p. 596-671, 1956. 
TAVARES, A. C. F., MORAES, J. F. L. de; ADAMI, S. F.; LOMBARDI NETO, F.; VALERIANO, M. de M. Expectativa de degradação dos recursos hídricos em microbacias hidrográficas com auxílio de sistemas de informação geográfica. Acta Scientiarum Agronomy, Maringá, v. 25, n. 2, p. 417-424, 2003.

VENTURIERI, A.; SANTOS, J. R. dos. Técnicas de classificação de imagens para análise de cobertura vegetal. In: ASSAD, E. D.; SANO, E. E. Sistema de informações geográficas. 2. ed. Brasília: EMBRAPA, 1998. p. 351-371. Capítulo 18.

VERDIN, K. L. A system for topologically coding global drainage basins and stream networks. In: ANNUAL ESRI USERS CONFERENCE, 17., July 1997, San Diego. Proceedings... Disponível em: <http://gis.esri.com/library/userconf/proc97/proc97/ to350/pap311/p311.htm>. Acesso em: 15 mar. 2006.

VERDIN, K. L.; VERDIN, J. P. A topological system for delineation and codification of the Earth's river basins. Journal of Hydrology, Amsterdam, v. 218, n. 1, p. 1-12,1999.

VILLELA, S. M.; MATTOS, A. Hidrologia aplicada. São Paulo: McGraw-Hill, 1975. 245p. 